$\underline{\text { Review Article }}$

\title{
NIOSOMES AS AN EMERGING FORMULATION TOOL FOR DRUG DELIVERY-A REVIEW
}

\author{
SARASWATHI T. S. ${ }^{a}$, MOTHILAL M. ${ }^{a^{*}}$, JAGANATHAN M. K. ${ }^{b}$
}

aDepartment of Pharmaceutics, SRM College of Pharmacy, SRM Institute of Science and Technology, Kattankulathur, Tamil Nadu, India, bDepartment of Biotechnology, School of Bioengineering, SRM Institute of Science and Technology, Kattankulathur, Tamil Nadu, India Email: mothipharma78@gmail.com

Received: 29 Oct 2018, Revised and Accepted: 30 Jan 2019

\section{ABSTRACT}

Nonionic surfactant based vesicles which are uni/multilamellar in structures are called niosomes. These vesicles contains an aqueous interior surrounded by one or more amphiphilic bilayer membrane forming surfactant which separates them from the bulk solution, and are also called as supramolecular aggregates. Niosomes, being an efficient drug delivery system, investigations are carried out to utilize this system to treat various disorders, to promote improved patient compliance, lesser side effects, reduction in dose, lesser dosage frequency, and higher amount of the drug at the particular site so as to lessen an excessive contact with the whole body. The Pharmacokinetic and Pharmacodynamic profile of Niosomal drug delivery system vary for various entrapped drugs. Drugs that are successful in the mitigation or treatment of CNS disorders should cross the BBB to reach the brain, as BBB seems to be an obstacle for a large number of drugs, including CNS active drugs. This article compiles recent techniques for the preparation and characterization of niosomes, the effect of formulation variables on its physicochemical properties and discussed about its effective applications in drug delivery.

Keywords: Niosome, Non-ionic surfactant, Drug delivery-targeted, Thin film hydration

(C) 2019 The Authors. Published by Innovare Academic Sciences Pvt Ltd. This is an open-access article under the CC BY license (http://creativecommons.org/licenses/by/4.0/) DOI: http://dx.doi.org/10.22159/ijap.2019v11i2.30534

\section{INTRODUCTION}

Nonionic surfactant based vesicles which are uni/multilamellar in structures enclosing lipophilic components and an aqueous solution of solutes are called niosomes. These vesicles are produced by the self-assembly of hydrated surfactant monomers. Compared to liposomes, niosomes overcomes the stability associated problems which includes oxidation, high economy, a purity that influences on size and shape. Niosomes are capable of entrapping both hydrophilic and lipophilic drugs in the aqueous layer and vesicular membrane and are represented in fig. 1 . The bilayers of niosomes have sandwiched lipophilic area in between the hydrophilic inner and outer surfaces of the bilayers. Hence drugs can be delivered extensively along with other required materials using niosomes. In recent years, these were extensively studied for their modified potential of the biodistribution and activity profile of the drug. It acts as a carrier in the release of medicaments, hormones, antigens, and bioactive molecules. Moreover, niosome also acts as an alternate version to unravel the problem of insolubility, unsteadiness and rapid deprivation of drugs [1].

Brain is a delicate organ, more efficiently protected by the nature by itself. Brain is protected against toxic substances by two major barrier systems namely the blood-brain barrier (BBB) and bloodcerebrospinal fluid barrier (BCSFB). The morphological and physiological characteristics of barriers are distinct, based on their different tasks [2]. Brain endothelia comprises of brain capillary endothelium forming "tight junctions"/zonulaoccludens is known as $\mathrm{BBB}$, which prevents migration or cell movement across endothelial cells [3]. As a result of its stringent permeability, it restricts the entry of hopeful drugs to target brain tissues and is accepted to be the key hurdle in mounting CNS drugs [4].

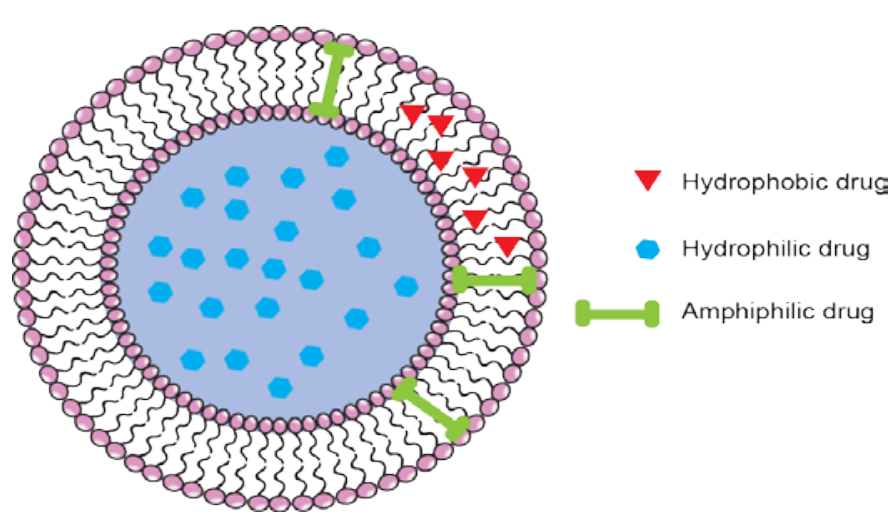

Fig. 1: Schematic representation of a Niosome

\section{Surfactants}

Surfactants and their combinations in various molar ratios are used to entrap numerous drug moieties in niosomes of varying sizes [5]. Nonionic surfactants have high interfacial activity and composed of both polar and nonpolar segments. Hydrophilic-lipophilic balance (HLB) of the surfactant, chemical structure of the components and critical packing parameter (CPP) are the key factors for the formation of bilayer vesicles [6].
Critical packing parameter can be determined by the self-assembly of surfactants to vesicles.

$$
C P P=V / I c a
$$

Hydrophobic tail volume (V), Hydrocarbon tail area (Ic), and Hydrophilic head group area (a) is also shown in fig. 2. 


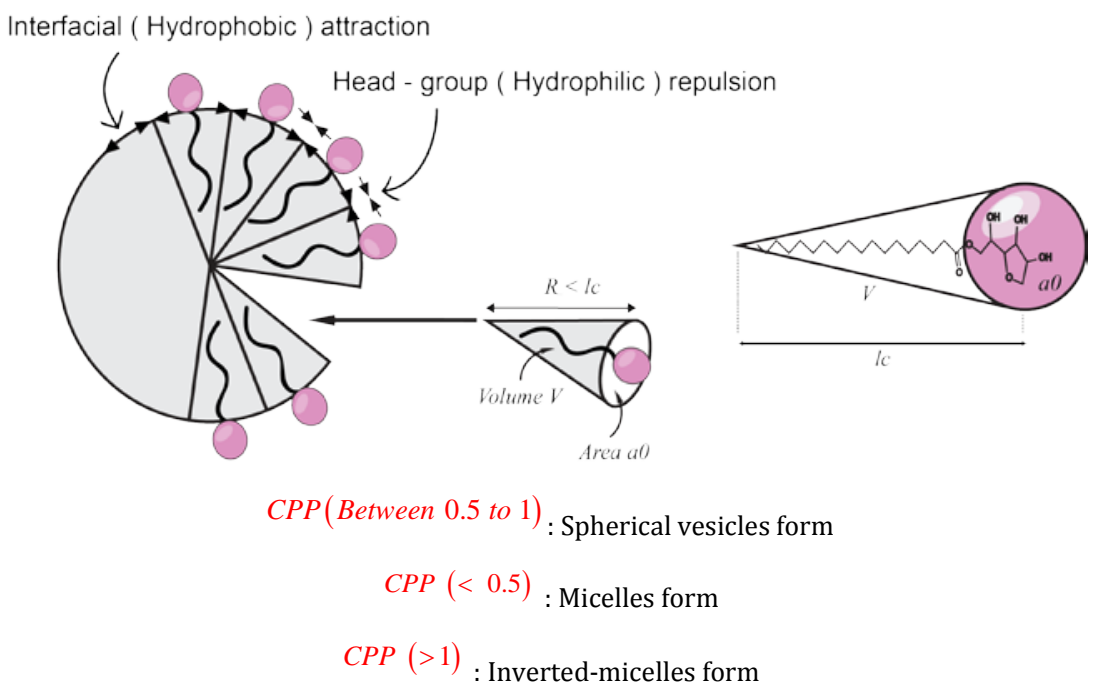

Fig. 2: Critical packing parameter [7]

Entrapment efficiency of the drug is highly affected by the size of the hydrophilic head group and chain length of the nonionic surfactant. Stearyl (C18) chains of nonionic surfactants showed merely higher entrapment-efficiency compared with lauryl chains (C12). Studies showed maximum entrapment efficiency for water-soluble drugs when various tweens bearing a long alkyl chain and a large hydrophilic moiety are combined with the Cholesterol [8].

\section{Ether-linked surfactants}

Polyoxyethylene alkyl ethers are surfactants in which hydrophilic and hydrophobic moieties are linked with ether group. The General formula of Polyoxyethylene alkyl ethers is CnEOm, where $n$ can be 1218 and $m$ can be 3-7. Surfactants with Polyhydroxyl head and ethylene oxide units are reported in various niosomal formulation [9].

The hydrophilic and hydrophobic group of the surfactant linked with ester moiety have been applied for the preparation of sodium stibogluconate and to deliver it towards the marine visceral leishmaniasis [10].

\section{Sorbitan esters}

Ester-linked surfactants are derivatives of Polyoxyethylene esters used in the cosmetic industry for the preparation of water-based products. They are also referred to as spans. Mostly the spans are used to solubilize the essentials oils which are used in cosmetic preparations. Spans with high molecular weight produces less leaky vesicles which are more stable to osmotic gradient [11].

\section{Alkyl amides}

Alkyl amides vesicles are supramolecular assemblies produced by incorporating amino acid spacers in alkyl galactosides and glucosides. Alkyl amides have alkyl groups that are fully/partially saturated hydrocarbons having a chain length of C12 to C22 with few fluorocarbon chains having newer amide like compounds [11].

\section{Fatty acids and amino acid compounds}

Amino acid moieties becomes amphiphilic when fatty acids are used. The vesicles are formed with hydrophobic alkyl side chains, whereas long chain fatty acids forms closed vesicles which are called as "Ufasomes" [11].

\section{Cholesterol}

An important component of a cell membrane showing noticeable changes in bilayer fluidity and permeability. Cholesterol is usually incorporated into non-ionic surfactants in large molar ratios to provide rigidity and orientational order. Cholesterol is an amphiphilic molecule, which orients the aliphatic chain in the direction of surfactant's hydrocarbon chain and $\mathrm{OH}$ group in the direction of the aqueous phase. Rigidization is provided by alternative positioning of a rigid steroidal skeleton with surfactant molecules in the bilayer. It also prevents leakage by eliminating gel to liquid phase transition [11].

\section{Charge inducers}

The stability of the vesicle is increased by charge induction on the surface of prepared vesicles. The zeta potential of vesicles are higher and it prevents the aggregation of vesicles due to the repulsive forces of the same charges. The frequently used positive charge inducers are cetyl pyridinium chloride and sterylamine and negative charge inducers are dihexadecyl phosphate, lipoamine acid and dicetyl phosphate [12].

\section{Choice of surfactant and stabilizer}

In the niosomal formulation, selection of surfactant and stabilizer plays the major role in the optimization of invitro release, required size distribution, entrapment efficiency and viscosity etc. Studies showed that zidovudine (BCS Class III) niosomes prepared with Tween 80 as surfactant and DCP as stabilizer (-ve charge-inducer) effectively entrapped high amounts of drug and released $88.72 \%$ of drug over $12 \mathrm{~h}$ [13]. Ammar HO et al. investigated that Diltiazem (BCS Class I) niosomes prepared with span 60 and Cholesterol (1:1 molar ratio) showed maximum entrapment efficiency and drug release on in-vitro investigation and in-vivo study exhibited an increase in MRT, t1/2 and AUC with a decrease in Ke [14].

Griseofulvin (BCS Class II) niosomes are prepared by thin film hydration technique with cholesterol, span 60, and DCP in the ratio of 75:75:1.5 exhibited maximum entrapment efficiency. In Griseofulvin niosomes, DCP imparts a negative charge to the bilayer vesicles as they are found to be more competent for drug delivery and provides stability to the system, prevents agglomeration and aggregation of vesicles [15].

Nagaraju Ravouru et al. developed Folic acid (BCS Class IV) niosomes for brain targeting with span60 and cholesterol (stabilizing agent) in the ratio of 1:1 (50 mg: $50 \mathrm{mg}$ ), showed the entrapment efficiency of about $69.42 \%$ with better in-vitro drug release profile of $64.2 \%$ at the end of $12 \mathrm{~h}$ [16].

\section{Techniques of preparation}

Vesicles of niosomes are produced by various techniques as shown in Fig.3. Some of the methods are suitable for large-scale, and others are suitable for small scale. 


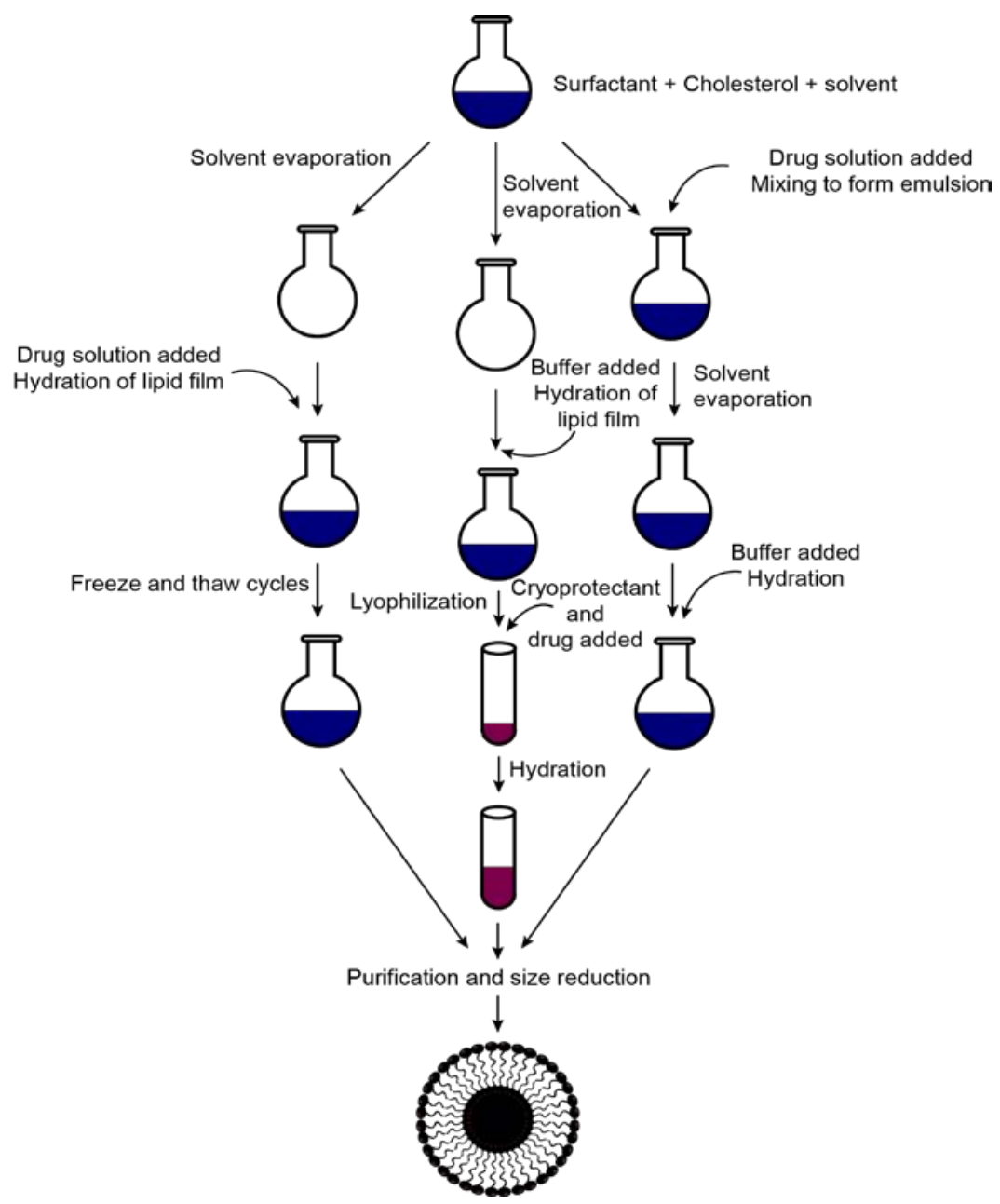

Fig. 3: Formulations of noisome

\section{Thin film hydration}

Surfactant, cholesterol and charge inducers are the vesicles forming components, are solubilised in a round bottom flask having an organic solvent which is volatile in nature. Formation of thin, dry film containing dissolved components is achieved by evaporating the organic solvent at room temperature using Rotovac evaporator. Formations of niosomes are achieved by hydration and gentle agitation of the dried thin film with aqueous phase $[17,18]$.

\section{Ether injection}

In this method, surfactant, cholesterol and other substances are solubilized in diethyl ether and slowly injected into an aqueous phase at $60^{\circ} \mathrm{C}$ using 14 gauge needle, leading to the evaporation of the ether and forming single layered vesicles. The control of the size of the vesicles can be observed by controlling the size of the needle and other conditions. This process finds its disadvantage of material solubilization in ether and removal of same from the final formulation with a great difficulty [19].

\section{Reverse phase evaporation}

In this process, surface active agents are solubilised in a mixture of organic solvents which is volatile in nature, such as ether and chloroform followed by the drug in an aqueous phase. Water in oil (W/O) emulsion of the two phases in a bath-sonicator yields niosomes upon evaporation of an organic solvent. The emulsion obtained from this process is dried in a Rotovac evaporator at $40{ }^{\circ} \mathrm{C}$ to form a semi-solid gel first and consequently hydrates to fig. large vesicles. A small quantity of buffer is added to the semi-solid gel and sonicated at $4-5{ }^{\circ} \mathrm{C}$ to produce unilamellar vesicles which are smaller in size [20].

\section{Microfluidization}

This technique involves an interaction chamber where two phases interact at ultra-high speed in microchannels. Niosomes which are small and uniform are formed due to high-speed impingement and the energy with a high degree of reproducibility [21].

\section{Sonication}

Surfactant-cholesterol mixture is dispersed in the aqueous phase. The dispersed phase is probe sonicated for $10 \mathrm{~min}$ at $60{ }^{\circ} \mathrm{C}$ to produce multilamellar vesicles (MLV), further increase in sonication time produce uni-lamellar vesicles [22, 23].

\section{The bubble method}

This is a single step process without the action of the organic solvent. A buffer is used for the all the components to disperse and kept in a three-necked round bottom flask attached to water cooled-reflux having the nitrogen supply along with a thermometer. The said flask was immersed in a water bath having controlled temperature. Finally, the dispersion was mixed with a shear homogenizer for 15 seconds and bubbled with nitrogen assembly to yield niosomes [24].

\section{Active trapping techniques}

In this method, the $\mathrm{pH}$ or ion gradient is maintained at optimum to yield niosomes having high drug-lipid ratios and absence of leakage with $100 \%$ entrapment efficiency. This is suitable for labile drugs [25].

\section{Tran's membrane $\mathrm{pH}$ gradient}

In this process, the components are solubilized in the organic phase and allowed to evaporate to form a thin layer. The thin layer is 
further hydrated with citric acid to produce multilamellar vesicles. The formed multilamellar vesicles are freeze-thawed three times and sonicated to form a suspension. To this suspension an aqueous solution containing drug is added, vortexed and $\mathrm{pH}$ was raised to 7.0-7.2 using $1 \mathrm{M}$ disodium phosphate. The suspension is subjected to $60^{\circ} \mathrm{C}$ for $10 \mathrm{~min}$ to produce drug loaded niosomes [26]

\section{Formation of niosomes from proniosomes}

The proniosomes are obtained as a dried product, in which sorbital is used as a water-soluble carrier and are coated with a thin film of dry non-ionic surfactants. They were renowned by the adding up of aqueous phase at $(\mathrm{T}>\mathrm{Tm})$ and concise confrontation concomitantly [27]

\section{$(T>\mathrm{Tm})$-(Temperature $>$ Mean phase transition temperature $)$}

\section{Multiple membrane extrusion methods}

This can be used for the production of multi as well as large unilamellar vesicles, and its size can be condensed by fleeting through a membrane filter. It is also a reliable way for the production of niosomes with controlled vesicle size [28].

\section{The handjani-vila method}

In this method, non-ionic synthetic lipids are mixed with an equivalent amount of drug aqueous solution to be encapsulated. The lipid-oil mixture is shaked to form a homogenous lamellar film. The mixture is further homogenized at a controlled temperature by using ultracentrifugation and agitation [29].

\section{The enzymatic method}

The ester links are cleaved by the esterases, and Cholesterol and surfactants such as polyoxyethylene cholesteryl sebacetate diacetate and Polyoxyethylene stearyl derivatives combine with diacetyl phosphate and other lipids to produce multilamellar niosomes [30].

\section{The single pass technique}

Michael W et al. patented a continuous process, in which the solution or suspension of lipids are extruded with high pressure through a porous device and a nozzle followed by homogenization to form niosomes of narrow range 50-500 $\mathrm{nm}$ size distribution [31].

Table 1: Methods of preparation with various Non-ionic surfactants and stabilizer with its applications

\begin{tabular}{|c|c|c|c|c|}
\hline Method & $\begin{array}{l}\text { Non-ionic surfactant and } \\
\text { stabilizer }\end{array}$ & Drug & Applications & Reference \\
\hline $\begin{array}{l}\text { Thin film-hydration } \\
\text { technique }\end{array}$ & Span 60, Cholesterol & Diltiazem & $\begin{array}{l}\text { Calcium channel blocker; hypertension, angina } \\
\text { pectoris, and some types of arrhythmia }\end{array}$ & 14 \\
\hline $\begin{array}{l}\text { Thin film-hydration } \\
\text { technique }\end{array}$ & Span 60 , Cholesterol & Diacerein & Inhibiting interleukin-1 beta; Osteoarthritis & 32 \\
\hline Sonication Method & $\begin{array}{l}\text { Span } 60 \text {, Cholesterol, } \\
\text { dicetylphosphare (DCP), } \\
\text { stearylamine (SA) }\end{array}$ & Candesartan & $\begin{array}{l}\text { Angiotensin II receptor antagonist; } \\
\text { Hypertension }\end{array}$ & 33 \\
\hline $\begin{array}{l}\text { Lipid film hydration } \\
\text { method }\end{array}$ & Span 60, Cholesterol & Loratadine & Antihistamine; Allergies & 34 \\
\hline $\begin{array}{l}\text { Thin film hydration } \\
\text { method, an Ether } \\
\text { injection method }\end{array}$ & Tween 40 , cholesterol & Ketoprofen & $\begin{array}{l}\text { Nonsteroidal anti-inflammatory drugs } \\
\text { (NSAID); Inhibiting synthesis of prostaglandin. } \\
\text { Analgesic and antipyretic effects. }\end{array}$ & 35 \\
\hline $\begin{array}{l}\text { Thin film-hydration } \\
\text { technique }\end{array}$ & $\begin{array}{l}\text { Span 60, Cholesterol, Solulan C } \\
24\end{array}$ & $\begin{array}{l}\text { Ketorolac } \\
\text { tromethamine }\end{array}$ & $\begin{array}{l}\text { NSAID; } \\
\text { To treat metabolic acidosis }\end{array}$ & 36 \\
\hline $\begin{array}{l}\text { Thin film-hydration } \\
\text { technique }\end{array}$ & $\begin{array}{l}\text { Span 60, Cholesterol, } \\
\text { Dicetylphosphate (DCP) }\end{array}$ & Tenofovir & To treat chronic (long term) HBV & 37 \\
\hline $\begin{array}{l}\text { Lipid layer hydration } \\
\text { method }\end{array}$ & Span 60, Cholesterol & Folic acid & Anaemia & 16 \\
\hline $\begin{array}{l}\text { Thin film hydration } \\
\text { technique }\end{array}$ & $\begin{array}{l}\text { Span 60, Cholesterol, } \\
\text { Dicetylphosphate (DCP) }\end{array}$ & Clarithromycin & To treat Bacterial infections & 38 \\
\hline $\begin{array}{l}\text { Thin film-hydration } \\
\text { technique }\end{array}$ & $\begin{array}{l}\text { Tween 80, Cholesterol, } \\
\text { Dicetylphosphate (DCP) }\end{array}$ & Zidovudine & $\begin{array}{l}\text { NRTIs; Nucleoside reverse transcriptase } \\
\text { inhibitors; to prevent passing the HIV to the } \\
\text { unborn baby in pregnant women }\end{array}$ & 15 \\
\hline $\begin{array}{l}\text { Lipid layer hydration } \\
\text { method, Thin film ether } \\
\text { injection method }\end{array}$ & $\begin{array}{l}\text { Span 60, Cholesterol, } \\
\text { Dicetylphosphate (DCP) }\end{array}$ & Griseofulvin & To treat skin infections & 13 \\
\hline $\begin{array}{l}\text { Thin film-hydration } \\
\text { technique }\end{array}$ & $\begin{array}{l}\text { Span 60, } \\
\text { Span 80, Cholesterol }\end{array}$ & Acyclovir & Anti-viral infections & 39 \\
\hline
\end{tabular}

Table 1 identified the important methods used to formulate the niosomes using various non-ionic surfactants and stabilizers. It also postulated that many of the niosomal formulations were prepared with span 60 as a non-ionic surfactant and cholesterol as a stabilizer for encapsulation of various drugs.

\section{Characterisation of niosomes}

\section{Morphology}

Niosomal vesicles shape is assumed to be spherical. Mean diameter can be determined by laser light scattering method [40]. The diameter of vesicles can also be determined by electron microscopy, freeze-fracture electron microscopy, molecular sieve chromatography, ultracentrifugation, photon correlation microscopy and optical microscopy [41, 42]. Fusion of vesicles during the cycle might be attributed to the increase in vesicle diameter due to freeze-thawing of niosomes.

\section{Bilayer formation}

X-cross formation under light polarisation microscopy characterizes the formation of bilayer vesicle owing to the assembly of non-ionic surfactants [43]. A diagrammatic representation of such formation is shown in fig. 4.

\section{Number of lamellae}

Determined by using nuclear magnetic resonance (NMR) spectroscopy, small angle X-ray scattering and electron microscopy [44].

\section{Membrane rigidity}

Measured by the mobility of a fluorescence probe as a function of temperature.

\section{Entrapment efficiency}

Once niosomal dispersion is formulated, an unentrapped drug is separated. The entrapped drug remained in niosomes is determined by complete vesicle disruption using $50 \% \mathrm{n}$-propanol/0.1\% Triton X100. The resultant solution is tested by appropriate assay method of the drug [45].

It can be represented as: 


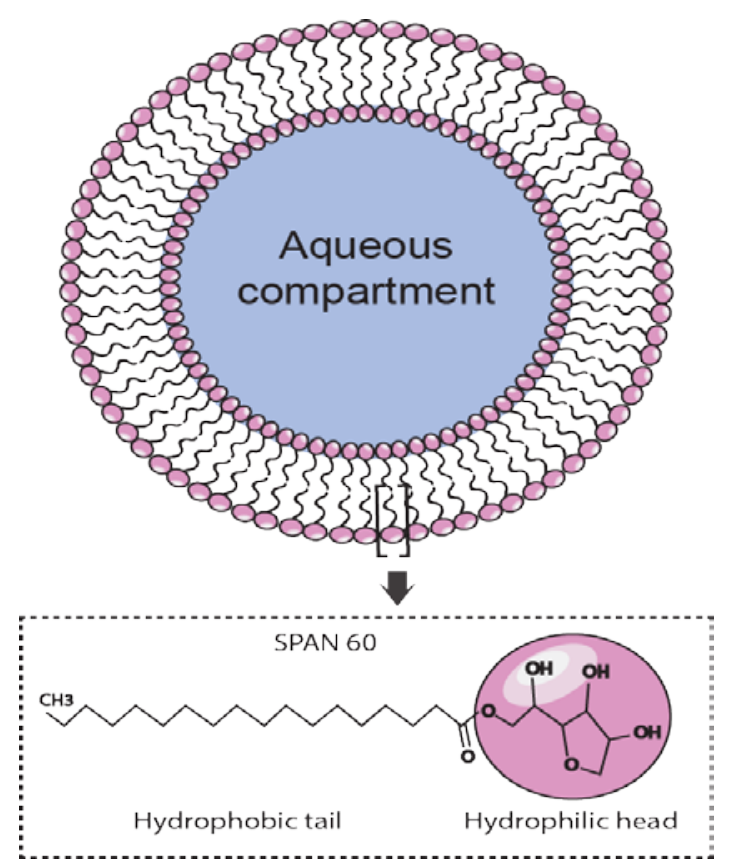

Fig. 4: Formation of bilayer assembly of span 60 noisome [43]

\section{In vitro release study}

In-vitro release rate study was reported by using dialysis tubing [46]. Initially, dialysis sac was washed with distilled water, followed by soaking, and the vesicle suspension was pipette into a bag made up of the tubing, finally sealed. In a $250 \mathrm{ml}$ beaker, the bag containing vesicles was placed in $200 \mathrm{ml}$ buffer solution at $25^{\circ} \mathrm{C}$ or $37^{\circ} \mathrm{C}$ with constant shaking. By an appropriate assay method with a range of time intervals, the buffer was analysed for the drug content.

Gel filtration technique was used for the separation of free Isoniazid from Isoniazid encapsulated niosomes using Sephadex G-50 powder soaked for $48 \mathrm{~h}$ in double distilled water for swelling [47]. In this process about $1 \mathrm{ml}$ of prepared niosomal suspension was placed over the top of the column and elution is carried out using normal saline. Followed by the free drug, a slightly dense, white opalescent suspension of encapsulated isoniazid niosomes elutes out. In a dialysis tube separated niosomes were filled and was attached to one end. Finally, dialysis tube was suspended in phosphate buffer of $\mathrm{pH}$ (7.4), with a frequent stirring with a magnetic stirrer. The samples were withdrawn at specific time intervals and tested using high-performance liquid chromatography (HPLC) method.

\section{In vivo release study}

In vivo release study was performed using albino rats. These albino rats were differentiated into various groups. By means of appropriate disposal syringe, a niosomal suspension was injected intravenously through a tail vein for in vivo study.

Table 2: Characterization parameters

\begin{tabular}{|c|c|c|c|}
\hline Parameters & Units & Instruments & Reference \\
\hline Particle size determination & $\mathrm{Nm}$ & Optical Microscopy, Dynamic light scattering & $16,36,37$ \\
\hline $\begin{array}{l}\text { Vesicle morphology and Size } \\
\text { analysis }\end{array}$ & $\mathrm{Nm}$ & $\begin{array}{l}\text { Transmission electron microscopy } \\
\text { Scanning electron microscope }\end{array}$ & $35,36,37$ \\
\hline Entrapment Efficiency & $\%$ & $\begin{array}{l}\text { Exhaustive dialysis method, Sephadex G-50 minicolumn centrifugation method, } \\
\text { Centrifugation method Refrigerated centrifuge Sonication Ultracentrifugation }\end{array}$ & $32,34,36$ \\
\hline Viscosity & poise & Ostwald's viscometer, Brookfield synchro electroviscometer & 33,34 \\
\hline Osmotic shock & $\mathrm{Nm}$ & Optical microscopy & 15,39 \\
\hline Invitro drug release & $\%$ & $\begin{array}{l}\text { Membrane diffusion Technique, Dialysis method, Spectrophotometric determination } \\
\text { Franz diffusion cell }\end{array}$ & 16,37 \\
\hline Stability studies & $\%$ & Drug retention behaviour & 16,37 \\
\hline Zeta potential & $\mathrm{mV}$ & $\begin{array}{l}\text { Zetasizer, Dynamic light scattering technology, NanoZS- } 90 \text { zetasizer, Malvern zetasizer } \\
\text { Nano ZS }\end{array}$ & 33,36 \\
\hline In vitro skin penetration study & $\%$ & Vertical franz-type diffusion cell & 32 \\
\hline Flow properties & - & Angle of repose & 34 \\
\hline Consolidation and compressibility & - & Hausner index (HI) & 35 \\
\hline Ex vivo and In vivo studies & $\%$ & Animal models & 36,37 \\
\hline
\end{tabular}

Table 2 summarizes the various parameters such as Particle size determination, Vesicle morphology and Size analysis, Entrapment Efficiency; stability studies etc., to assure the niosomal drug delivery system as a competent approach towards the novel drug delivery.

\section{Formulations and routes of administration}

In designing a vesicular formulation, the route of administration plays a major role. Among the various types of formulations, niosomes can be one of the potential oral drug delivery. Niosomes of gliclazide being a promising delivery system with enhanced bioavailability and prolonged drug release profile for the treatment of diabetes mellitus [48].

Transdermal therapeutic systems are effective dosage forms as they are self-contained and self-discrete dosage forms. They deliver the drug when applied to the intact skin in a controlled rate into the systemic circulation with a slow penetration, a major downside of transdermal drug delivery. In this case, niosomes can effectively increase the penetration rate when the transdermal delivery of the drug is incorporated. Using thin film hydration technique, and with various ratios of non-ionic surfactants such as Tween 20, Tween 40 , Tween 60, and Tween 80 niosomes of terbinafine hydrochloride was formulated [49]. Some of the recent reports on brain-targeted drug delivery on Nanoemulsion includes Palperidone or curcumin microemulsion [50] or Quetiapine nanoemulsion [51].
Gel formulation is quite eminent for intranasal delivery. Various polymers comprising synthetic/natural polymers are converted into gel form by shifting $\mathrm{pH} /$ temperature are used in gel formulations [52]. Drugs such as Ropinirole [53], Levadopa [54], Midazolam [55] have been developed as an in-situ nasal thermoresponsive gel delivery system and showed efficient brain-targeted drug delivery via intranasal route. However, the effect of temperature on such dosage form needs significant assessment [56].

\section{Niosomes-advantages}

Niosomes offers better patient compliance and therapeutic effect with greater bioavailability compared to conventional dosage forms $[57,58]$. The depot formation of noisome shows controlled and sustained release of drugs $[59,60]$. The remarkable capability of noisome is to entrap hydrophilic drugs, lipophilic drugs as well as amphiphilic drugs [61]. The size, shape, fluidity, composition, of drug-containing niosomes can be controlled whenever necessary.

Niosomes are successfully used in targeting drugs to several organs [62]. Compared to liposomes, niosomes are more stable [63] and can raise the permeation of drugs in the skin [64]. The routes of administration of 
niosomes can be widened like oral, parenteral and topical etc. [65]. Niosomes are biodegradable, biocompatible and non-immunogenic to the body. In the case of niosomes the handling, storage, and transportation are quite easier than any other formulations [66].

Table 3: Non-ionic surfactants with various routes of administration

\begin{tabular}{lllll}
\hline Non-ionic surfactant & Stabilizer & Ratio & Route of administration & Reference \\
\hline Span 60 & Cholesterol & $1: 1$ & Nasal & 14 \\
Span 60 & Cholesterol & $9: 1$ & Topical & 32 \\
Span 60 & Cholesterol, Dicetylphosphate (DCP) & $1: 1: 0.05$ & Oral & 33 \\
Span 60 & $1: 1$ & Nasal & 34 \\
Tween 40 & Cholesterol & $1: 1$ & Topical & 35 \\
Span 60 & Cholesterol & $1: 1$ & Topical & 36 \\
Span 60 & Cholesterol & $1: 1$ & Oral & 37 \\
Span 60 & Cholesterol, Dicetylphosphate (DCP) & $1: 1$ & Nasal & 16 \\
Span 60 & Cholesterol & $1: 1$ & Oral & 38 \\
Span 60 & Cholesterol & $75: 75: 1.5$ & Oral & 13 \\
Span 60 And Span 80 & Cholesterol, Dicetylphosphate (DCP) & $1: 2: 1$ & Topical & 39 \\
\hline
\end{tabular}

From the table 3 it is understood that niosomes are successfully employed in the oral and topical formulations and recently niosomal formulations are being employed via nasal route.

\section{Application of niosomes}

Niosomes have been widely applied in diverse fields to treat various diseases, diagnostics, and cosmetics. Niosomes have a wide range of pharmaceutical drug delivery application owing to their inherent advantages.

\section{Immuno-niosomes}

Niosomes conjugation to antibodies forms immune-niosomes on their surface. Incorporation of cyanuric chloride derivatized Tween 61 in the noisome formulation was done through monoclonal IgG antibodies conjugated to the vesicle surfaces, and are prepared using thin film hydration techniques followed by sonication.

\section{Magnetic niosomes}

Niosomes show its effective magnetic targeting in a combination of drug delivery for various applications especially in cancer therapy [67]. Encapsulation of both anti-tumoral model drug and magneticEMG 707 ferrofluids into the aqueous core of niosome, lead to the development of Doxorubicin-loaded magneto-niosomal formulations without any additional toxicity [68].

\section{Gene delivery}

Niosomes are utilized as a cutaneous gene delivery system for the treatment of skin diseases [69]. In a study by Raghavachari and Fahl [70], nonionic liposomes in rat skin cells; affords a competent delivery of beta-galactosidase/luciferase DNAs and it is illustrated as that generally DNA is a sequence of base-pairs of four different nucleotide bases [71].

\section{Anticancer drug delivery}

Niosomes comprising a non-ionic surfactant, cholesterol and dicetyl phosphate encapsulating methotrexate (MTX) lead to the increased absorption from the gastrointestinal tract with subsequent oral ingestion. Excessive uptake of MTX into the liver following the intravenous administration of the niosomes as compared to MTX, administered either orally or intravenously.

Other anticancer agents such as vincristine [72] bleomycin [73] and paclitaxel [74] show reduced toxicity with improved anticancer activity.

\section{Transdermal delivery}

Stratum corneum, the intracellular lipid barrier is significantly looser and more permeable for the particles such as niosomes [75]. Niosomes were used as a carrier for the transdermal delivery of ketorolac-a potent nonsteroidal anti-inflammatory drug with significant improvement in drug permeation with reduced lag time [76].

Ammonium glycyrrhizinate, niosomes of the natural compound, having effective anti-inflammatory activity formulated with the help of a new nonionic surfactant, ậ $\omega$-hexadecyl-bis-(1-aza-18-crown-6) (bola surfactant)-span 80 and cholesterol in a ratio of 2: 3: 1 to increase the intracellular delivery by bola surfactant. Experiments showed that the bola niosomes could promote the intracellular uptake of ammonium glycerrhizinic acid [77].

\section{Improved stability of peptide drugs}

Stability of peptide drug namely, 8-arginin vasopressin, 9glycinamide-w 33 was increased significantly by using niosomes. A non-ionic surfactant Span 60 has high conflicts in incorporating proteolytic enzymes, but in the presence of sodium deoxycholate and proper storage temperature, the stability of niosomes is found to be excellent [78].

\section{In ophthalmic drug delivery}

Gentamicin sulphate, a water-soluble antibiotic shows an extensive alteration in the release rate during its experimental studies. Moreover, in contrast to the regular drug sample solution, niosomal formulation of drug exhibit sluggish release [79]. Timolol maleate $(0.25 \%)$ niosomes, formulated via coating with chitosan shows more effect on intraocular tension with fewer side effects as compared to the marketed products [80].

\section{In the treatment of localized psoriasis}

The limited applications of Methotrexate for the treatment of psoriasis were because of its manufacturing difficulties. It was then overcome by methotrexate niosomes, using chitosan as the polymer, with the promising results [81].

\section{In leishmaniasis}

Generally, leishmaniasis parasite primarily affects the cells of the liver and spleen. Antimonials, the commonly used drug may damage the heart; liver; kidney etc. The incorporation of these drugs like sodium stibogluconate into niosomes improves the efficacy of the drug [82]. The additive effect was observed when two doses were given on successive days. Moreover, the higher level of antimony in the liver after its intravenous (i. v.) administration in mice is found in niosomes drug formulation [83].

\section{In diagnostic imaging}

Niosomes-as a carrier for radiopharmaceuticals. It also shows site specificity for spleen and liver using $99 \mathrm{mTc}$ labelled DTPA containing niosomes for their imaging studies [84]. Improved tumour targeting of a paramagnetic agent is obtained by conjugated niosomal formulations-gadobenate with (N-palmitoyl-glucosamine, NPG), PEG 4400 and both PEG and NPG [85].

\section{Carrier for haemoglobin}

Niosomes being a carrier for haemoglobin plays a major role. A super-imposable curve on free haemoglobin curve is obtained by the niosomal haemoglobin suspension [86, 87]. 


\section{Cosmetic delivery}

L'Oréal developed and patented niosomes in the year 1970s and 1980s who devised the primary report of non-ionic surfactant vesicles for cosmetic applications. And the first product 'Niosome' was introduced in 1987 by Lancôme. Niosomes have intense ability to progress the bioavailability of poorly absorbed substances; raise the stability of entrapped drugs and finally enhances skin penetration, thus paves the way for niosomes in the area of cosmetic and skin care applications [88].

\section{Vaccine delivery}

For peroral vaccine delivery system and for topical immunization, niosomes attains good attention. Niosomes for topical DNA delivery of Hepatitis B surface antigen (HBsAg) were formulated, using the reverse phase evaporation method using Span 85 and cholesterol. The immune stimulating activity was investigated and was noted that topical niosomes elicited a comparable serum antibody titer and endogenous cytokines levels as compared to topical liposomes and intramuscular (i. m) recombinant HBsAg $[89,90]$.

\section{CONCLUSION}

Niosomes are becoming an efficient and effective move towards a recent drug delivery. These were used in the modern pharmaceutical industry due to their remarkable advantages over conventional vesicular delivery systems. Among all the applications of niosomal technology, the development of a suitable niosomal carrier to encapsulate neuroactive compounds is incredibly promising. The nose to brain delivery route has the potential to become alternative of invasive methods of drug delivery to the brain regarding improved drug absorption and less systemic adverse effect. To enjoy the advantages, the limitations of variable absorption or nasal toxicity must be exterminated. The goal of development of niosomes is to control the release of drug in a sustained manner, a further change in the distribution profile of drug and targeting to the specific body site. Thus as an effective tool now and then for various therapeutic substances and the responsibility lies on future research scientists to successfully yoke its potential in various purposes for the aid of people.

\section{ACKNOWLEDGMENT}

The authors are thankful to SRM College of Pharmacy, SRM University, Kattankulathur, Tamilnadu.

\section{AUTHORS CONTRIBUTIONS}

All the author have contributed equally

\section{CONFLICT OF INTERESTS}

All authors declare that there is no conflict of interest associated with this article.

\section{REFERENCES}

1. Biju SS, Talegaonkar S, Mishara PR, Khar RK. Vesicular systems: an overview. Indian J Pharm Sci 2010;210:141-51.

2. Pardridge WM. Blood-brain barrier drug targeting: the future of brain drug development. Mol Interv 2003;3:90-105.

3. Ulrich Bickel, Young Sook Kang, Jorg Huwyler. Drug targeting organ-specific strategies. Edited by G Molema, DKF Meijer. Chapter 2 Brain-Specific Drug Targeting Strategies; 2001. p. 2350.

4. Shadab A Pathan, Zeenat Iqbal, Syed MA Zaidi A, Sushma Talegaonkar, Divya Vohra. CNS drug delivery systems: novel approaches. Recent Pat Drug Delivery Formulation 2009;3:7189.

5. Giddi HS, Arunagirinathan MA, Bellare JR. Self-assembled surfactant nano-structures are important in drug delivery: a review. Indian J Exp Biol 2007;45:133-59.

6. Uchegbu IF, Double JA, Kelland LR, Turton JA, Florence AT. The activity of doxorubicin niosomes against an ovarian cancer cell line and three in vivo mouse tumour models. J Drug Target 1996;3:399-409.
7. Gannu P Kumarn, Pogaku Rajeshwarrao. Nonionic surfactant vesicular systems for effective drug delivery-an overview. Acta Pharma Sinica B 2011;1:208-19.

8. Arunothayanun P, Bernard MS, Craig DQ Uchegbu IF, Florence AT. The effect of processing variables on the physical characteristics of non-ionic surfactant vesicles (niosomes) formed from a hexadecyl diglycerol ether. Int J Pharm 2000;201:7-14

9. Vyas SP, Khar RK. Targeted and controlled drug delivery novel carrier systems; CBS Publishers and Distributors, New Delhi; 2011. p. 249-79.

10. Hunter CA, Dolan TF, Coombs GH, Baillie AJ. Vesicular systems (niosomes and liposomes) for delivery of sodium stibogluconate in experimental murine visceral leishmaniasis. J Pharm Pharmacol 1988;40:161-5.

11. Dahiya NK, Rao R, Nanda S. Preparation and characterization techniques in the niosomal vesicular systems-a review. J Pharm Biomed Sci 2011;5:1-8.

12. Bandyopadhyay P, Johnson M. Fatty alcohols or fatty acids as niosomal hybrid carrier: effect on vesicle size, encapsulation efficiency and in vitro dye release. Colloids Surf B Biointerfaces 2007;58:68-71.

13. Kandasamy Ruckmani, Veintramuthu Sankar. Formulation and optimization of zidovudine niosomes. AAPS PharmaSciTech 2010;11:1119-27.

14. Ammar HO, Haider M. In vitro and in vivo investigation for optimization of niosomal ability for sustainment and bioavailabilty enhancement of diltiazem after nasal administration. Drug Delivery 2017;24:414-21.

15. Pratap S Jadon, Virendra Gajbhiye, Rajesh S Jadon. Enhanced oral bioavailabilty of griseofulvin via niosomes. AAPS PharmSciTech 2009;10:4.

16. Nagaraju Ravouru, Pallavi Kondreddy, Deepathy Korakanchi, Haritha M. Formulation and evaluation of niosomal nasal drug delivery system of folic acid for brain targeting. Curr Drug Discovery Technol 2013;10:210-82.

17. Baillie AJ, Coombs GH, Dolan TF, Laurie J. Non-ionic surfactant vesicles, niosomes, as a delivery system for the anti-leishmanial drug, sodium stibogluconate. J Pharm Pharmacol 1986;38:502-5.

18. Astrid Permatasari Isnan, Mahdi Jufri. Formulation of niosomal gel containing green tea extract (camellia sinensis l. kuntze) using thinlayer hydration. Int J Appl Pharm 2017;9 Suppl 1:38-43.

19. Yasin MN, Hussain S, Malik F, Hameed A, Sultan T, Qureshi F, et al. Preparation and characterization of chloramphenicol niosomes and comparison with chloramphenicol eye drops $(0.5 \% \mathrm{w} / \mathrm{v})$ in experimental conjunctivitis in albino rabbits. Pak J Pharm Sci 2012;25:117-21.

20. Guinedi AS, Nahed DM, Samar M, Rania MH. Preparation and evaluation of reverse-phase evaporation and multilamellar niosomes as ophthalmic carriers of acetazolamide. Int J Pharm 2005;306:71-82.

21. Khandare JN, Madhavi G, Tamhankar BM. Niosome: a future of targeted drug delivery systems. The East Pharma 1994;37:61-4.

22. Vyas SP, Khar RK. Targeted and control drug delivery. 1st ed. Chap. 6, CBS Publishers and Distributors, New Delhi; 2002. p. 249-76.

23. Baillie AJ, Florence AT, Hume LR, Muirhead GT, Rogerson A. The preparation and properties of niosomes--non-ionic surfactant vesicles. J Pharm Pharmacol 1985;37:863-8.

24. Chauhan S, Luorence MJ. The preparation of polyoxyethylene containing non-ionic surfactant vesicles. J Pharm Pharmacol 1989;41:6.

25. Udupa N. Niosomes as drug carriers. In: NK Jain. Controlled and novel drug delivery, New Delhi: CBS Publishers and Distributors; 2009. p. 292-303.

26. Mayer LD, Bally MB, Hope MJ, Cullis PR. Uptake of antineoplastic agents into large unilamellar vesicles in response to a membrane potential. Biochem Biophys Acta 1985;816:294-302.

27. Blazek Walsh AI, Rhodes DG. SEM imaging predicts the quality of niosomes from maltodextrin-based proniosomes. Pharm Res 2001;18:656-61.

28. Junyaprasert VB, Teeranachaideekul V, Supaperm T. Effect of charged and non-ionic membrane additives on 
physicochemical properties and stability of niosomes. AAPS PharmSciTech 2008;9:851-9.

29. Almira I, Blazek Welsh IA, Rhodes GD. Maltodextrin-based proniosomes. AAPS PharmSciTech 2001;3:1-8.

30. Alemayehu T, Nisha MJ, Palani S, Anish Z, Zelalem A. Niosomes in targeted drug delivery: some recent advances. Int J Pharm Sci Res 2010;1:1-8.

31. Uchegbu IF, Vyas SP. Non-ionic surfactant based vesicles (niosomes) in drug delivery. Int J Pharm 1998;172:33-70.

32. Moghddam SR, Ahad A, Aqil M, Imam SS, Sultana Y. Formulation and optimization of niosomes topical diacerin delivery using 3factor, 3-level. Box-Behnken design for the management of psoriasis. Mater Sci Eng C Mater Biol Appl 2016;69:789-97.

33. Yuksel N, Bayindir ZS, Aksakal E, Ozcelikay AT. Insitu Niosome forming maltodextrin proniosome of candesartan cilexetil: In vitro and in vivo evaluation of in-situ niosome forming proniosomes containing candesartan cilexetil. Int J Biol Macromol 2015;82:453-63.

34. Vyshnavi V, Indira S, Prathima Srinivas. Formulation and evaluation of nasal niosomal in-situ gels of loratidine. Int J Pharm Sci Drug Res 2015;7:13-2.

35. Kaushik Kar, Preethi Sudheerl. Formulation and evaluation of niosomal drug delivery system of ketoprofen. J Pharm Sci 2015;5:173-80.

36. Ajay Aggarwal, Kamal Saroha, Sanju Nanda. Formulation, evaluation, and comparison of ketorolac tromethamine transdermal gel containing natural and synthetic permeation enhancers. Der Pharmacia Sinica 2014;5:41-5.

37. Sunil Kamboj, Vipin Saini, Suman Bala. Formulation and characterization of drug loaded non-ionic surfactant vesicles (Niosomes) for oral bioavailabilty enhancement. Sci Wor 2014:8. http://dx.doi.org/10.1155/2014/959741

38. Okore VC, Attarna AA, Ofokansi KC, Esimone CO. Formulation and evaluation of Niosomes. Ind J Pharm Sci 2011;73:323-8.

39. Rajalakshmi SV, Vinaya OG. Formulation development, evaluation and optimization of medicated lip rouge containing niosomal acyclovir for the management of recurrent herpes labialis. Int J Appl Pharm 2017;9:21-7.

40. Michael W, Gerhard W, Heinrich H, Klaush D. Liposome preparation by the single-pass process. US patent 20100316696 A1; 2010.

41. Biswal S, Murthy PN, Sahu J, Sahoo P, Amir F. Vesicles of nonionic surfactants (Niosomes) and drug delivery potential. Int J Pharm Sci Nanotech 2008;1:1-8.

42. Azmin MN, Florence AT, Handjani-Vila RM, Stuart JF, Vanlerberghe G, Whittaker JS. The effect of non-ionic surfactant vesicle (niosome) entrapment on the absorption and distribution of methotrexate in mice. J Pharm Pharmacol 1985;37:237-42.

43. Manosroi A, Wongtrakul P, Manosroi J, Sakai H, Sugawara F, Yuasa $\mathrm{M}$, et al. Characterization of vesicles prepared with various non-ionic surfactants mixed with cholesterol. Colloids Surf 2003;30:129-38.

44. Biswal S, Murthy PN, Sahu J, Sahoo P, Amir F. Vesicles of nonionic surfactants (Niosomes) and drug delivery potential. Int J Pharma Sci Nanotechnol 2008;1:1-8.

45. Balasubramaniam A, Kumar VA, Pillai KS. Formulation and in vivo evaluation of niosome-encapsulated daunorubicin hydrochloride. Drug Dev Ind Pharm 2002;28:1181-93.

46. Yoshioka T, Stermberg B, Florence AT. Preparation and properties of vesicles (niosomes) of sobitan monoesters (Span 20, 40,60, and 80) and a sorbitan triester (Span 85). Int J Pharm 1994;105:1-6.

47. Karki R, Mamatha GC, Subramanya G, Udupa N. Preparation, characterization and tissue disposition of niosomes containing isoniazid. Rasayan J Chem 2008:1:224-7.

48. Akhter S, Kushwaha S, Wrasi MH, Anwar M, Ahmad MZ, Ahmad $\mathrm{I}$, et al. Development and evaluation of nanosized niosomal dispersion for oral delivery of ganciclovir. Drug Dev Ind Pharm 2012;38:84-92.

49. Sathali AAH, Rajalakshmi G. Evaluation of transdermal targeted niosomal drug delivery of terbinafine hydrochloride. Int J Pharm Tech Res 2010;2:2081-9.
50. Shinde RL, Devarajan PV. Docosahexaenoic acid-mediated, targeted and sustained brain delivery of curcumin microemulsion. Drug Delivery 2017;24:152-61.

51. Boche M, Pokharkar V. Quetiapine nanoemulsion for intranasal drug delivery: evaluation of brain-targeting efficiency. AAPS PharmSciTech 2016. Doi:10.1208/s12249-016-0552-9

52. Karavasili C, Fatouros DG. Smart materials: in situ gel-forming systems for nasal delivery. Drug Discovery Today 2016;21:15766.

53. Rao M, Agrawal DK, Shirsath C. Thermoreversible mucoadhesive in situ nasal gel for the treatment of Parkinson's disease. Drug Dev Industrial Pharm 2017;43:1.

54. Sharma S, Lohan, Murthy RSR. Formulation and characterization of intranasal mucoadhesive nano particulates and thermo-reversible gel of levodopa for brain delivery. Drug Dev Ind Pharm 2014;40:869-78.

55. Parhizkar E, Emadi L, Alipour S. Development and evaluation of midazolam in situ nasal gel properties in presence of solubility enhancers at cilia-friendly $\mathrm{pH}$. Macromolecular Research 2017;25:255-61.

56. Morsi N, Ghorab D, Refai H, Teba H. Ketoroloac tromethamine loaded nanodispersion incorporated into thermosensitive in situ gel for prolonged ocular delivery. Int J Pharm 2016;506:57 67.

57. http://www.pharmainfo.net/reviews/non-ionic-surfactantbased-vesicle-niosome-potential-ocular-drug-delivery-systemoverview. [Last accessed on 20 Sep 2018]

58. Ismail AA, Sanaa A, Gizawy E, Fouda MA, Donia MA. Influence of a niosomal formulation on the oral bioavailability of acyclovir in rabbits. AAPS PharmSciTech 2007;8:206-12.

59. The Physical Chemistry of Membranes. ed. by Silver B, L Allen and Unwin, Boston-London-Sydney; 1985.

60. Haran G, Coben R, Bar LK, Barenholz Y. Vesicular drug delivery system-an overview. Biophys Acta 1993;1151:201.

61. Verma S, Singh SK, Syan N, Mathur P, Valecha V. Nanoparticle vesicular systems: a versatile tool for drug delivery. J Chem Pharm Res 2010;2:496-509.

62. Azmin MN, Florence AT, Handjani Vila RM, Stuart JFB, Vanlerberghe G, Whittaker JS. The effect of non-ionic surfactant vesicle (niosome) entrapment on the absorption and distribution of methotrexate in mice. J Pharm Pharmacol 1985;37:237-42.

63. Biswal S, Murthy PN, Sahu J, Sahoo P, Amir F. Vesicles of nonionic surfactants (Niosomes) and drug delivery potential. Int J Pharm Sci Nanotech 2008;1:1-8.

64. Mura S, Pirot F, Manconi M, Falson F, Fadda AM. Liposomes and niosomes as potential carriers for dermal delivery of minoxidil. J Drug Target 2007;15:101-8.

65. http://www.pharmainfo.net/reviews/niosome-unique-drugdeliverysystem. [Last accessed on 20 Sep 2018]

66. http://www.pharmainfo.net/reviews/non-ionic-surfactantbased-vesicle-niosome-potential-ocular-drug-delivery-systemoverview. [Last accessed on 20 Sep 2018]

67. Hood E, Gonzalez M, Plaas A, Strom J, VanAuker M. Immunotargeting of nonionic surfactant vesicles to inflammation. Int J Pharm 2007;339:222-30.

68. Kong MH, Park C, Feng L, Hou X, Cheng X Chen. Construction of hyaluronic acid noisome as functional transdermal nanocarrier for tumor therapy. Carbohydrate Polymers 2013;94:634-41.

69. Tavano L, Vivacqua M, Carito V, Muzzalupo R, Caroleo MC, Nicoletta F. Doxorubicin loaded magneto-niosomes for targeted drug delivery. Colloids Surf B Biointerfaces 2013;102:803-7.

70. Geusens B, Strobbe T, Bracke S, Dynoodt P, Sanders N, Van Gele $\mathrm{M}$, et al. Lipid-mediated gene delivery to the skin. Euro J Pharm Sci 2011;43:199-211.

71. Raghavachari N, Fahl W. Targeted gene delivery to skin cells in vivo: a comparative study of liposomes and polymers as delivery vehicles. J Pharm Sci 2002;91:615-22.

72. Mohebbi M, Akbarzadeh T, Fard A, Mohammad R. Microorganism DNA pattern search in a multi-agent genomic engine framework. Wor Appl Sci J 2007;2:582-86.

73. Parthasarathi G, Udupa N, Umadevi P, Pillai G. Niosome encapsulated of vincristine sulfate: improved anticancer 
activity with reduced toxicity in mice. J Drug Target 1994;2:173-82.

74. Raja N, Udupa N, Uma D. Effect of macrophage activation on niosome encapsulated bleomycin in tumor-bearing mice. Ind J Pharmacol 1996;28:175-80.

75. Bayindir ZS, Yuksel N. Characterization of niosomes prepared with various nonionic surfactants for paclitaxel oral delivery. J Pharm Sci 2010;99:2049-60.

76. Barry BW. Novel mechanisms and devices to enable successful transdermal drug delivery. Eur J Pharma Sci 2001;14:101-14.

77. Alsarra IA, Bosela AA, Ahmed SM, Mahrous GM. Proniosomes as a drug carrier for transdermal delivery of ketorolac. Eur J Pharma Biopharma 2005;59:485-90.

78. Junyaprasert VB, Teeranachaideekul V, Supaperm T. Effect of charged and non-ionic membrane additives on physicochemical properties and stability of niosomes. AAPS Pharm SciTech 2008;9:851-9.

79. Varshosaz J, Pardakhty A, Hajhashemi VI, Najafabadi AR. Development and physical characterization of sorbitan monoester niosomes for insulin oral delivery. Drug Delivery 2003;10:251-62.

80. Abdelbary G, El-Gendy N. Niosome-encapsulated gentamicin for ophthalmic controlled delivery. AAPS PharmSciTech 2008;9:740-7.

81. Aggarwal D, Garg A, Kaur IP. Development of a topical niosomal preparation of acetazolamide: preparation and evaluation. J Pharm Pharmacol 2004;56:1509-17.

82. Lakshami PK, Gayathri SD, Bhaskaran S, Sacchdanand S Niosomal methotrexate gel in the treatment of localized psoriasis: phase I and phase II studies. Indian J Dermatol Venerol Leprol 2007;73:157-61.
83. Hunter CA, Dolan TF, Coombs GH, Baillie AJ. Vesicular systems (niosomes and liposomes) for delivery of sodium stibogluconate in experimental murine visceral leishmaniasis. J Pharm Pharmacol 1988;40:161-5.

84. Yoshioka T, Stermberg B, Florence AT. Preparation and properties of vesicles (niosomes) of sorbitan monoesters (Span 20, 40,60 and 80) and a sorbitan triester (Span 85). Int J Pharm 1994;105:1-6.

85. Korkmaz M, Ozer AY, Hincal AA. DTPA niosomes in diagnostic imaging. ed. by Uchegbu IF. Harwood Academic Publishers, Singapore; 2000. p. 227-42.

86. Luciani A, Olivier JC, Clement O, Siauve N, Brillet PY, Bessoud B, et al. Glucose-receptor MR imaging of tumors: study in mice with PEGylated paramagnetic niosomes. Radiology 2004;231:135-42.

87. Moser P, Marchand Arvier M, Labrude P, Handjani Vila RM, Vignerson C. [Hemoglobin niosomes. I. preparation, functional and physicochemical properties, and stability]. Pharm Acta Helv 1989;64:192-202.

88. Moser P, Marchand Arvier M, Labrude P, Vigneron C. Hemoglobin niosomes. II. In vitro interactions of plasma proteins and phagocytes. Pharm Acta Helv 1990;65:82-92.

89. Buckton G. Interfacial phenomena in drug delivery and targeting. In: Florence AT, Gregoriadis G. Eds. Harwood Academic Publishers, Switzerland; 1995. p. 154-5.

90. Vyas SP, Singh RP, Jain S, Mishra V, Mahor S, Singh P, et al. Nonionic surfactant based vesicles (niosomes) for non-invasive topical genetic immunization against hepatitis B. Int J Pharm 2005;296:80-6. 